\title{
Experiência das Narrativas Cross e Transmidiáticas no Webjornalismo ${ }^{1}$
}

\section{Cross and Transmedia Narrative's Experience on Webjournalism}

\author{
Allysson Viana Martins I allyssonviana@gmail.com \\ Mestrando em Comunicação e Cultura Contemporâneas da UFBA. Jornalista pela UFPB. \\ Integrou o PIBIC de 2008 a 2010, estudando acerca da blogosfera, webjornalismo \\ e Teoria do Jornalismo. Na monografia, tratou das narrativas crossmidiáticas e \\ transmidiáticas e das propriedades do webjornalismo. Publicou, em organização \\ com Cláudio Cardoso de Paiva e Marina Magalhães de Morais, o livro "Afrodite no \\ ciberespaço: A era das convergências", contendo também artigo de sua autoria.
}

\section{Resumo}

O jornalismo não adquiriu só novas características quando se apropriou da web para produzir seu material. Especificidades inéditas e formas de construção do conteúdo também aparecem, ainda que algumas dessas novidades já existam - em outros meios e outras áreas. Aqui, diferenciamos conceitual e empíricamente as narrativas crossmidiáticas e transmidiáticas, discutindo a aplicabilidade de ambas no webjornalismo. Palavras-Chave: Transmídia; Crossmídia; Narrativas Midiáticas; Webjornalismo.

\begin{abstract}
Not only new characteristics journalism acquired when it appropriatedfrom the Web to produce its material. Unpublished specificities and forms of construction of the contents also appear, though some of these innovations already exist - in other media and areas. In this work, we differentiate conceptual and empirical crossmediatics and transmediatics narratives, discussing the applicability of both in Webjournalism.
\end{abstract}

Keywords: Transmedia; Crossmedia; Media narratives; Webjournalism 


\section{Introdução}

A convergência é atualmente uma expressão bastante utilizada em textos acadêmicos. Para os pesquisadores Antikainen et al. (2004, p.8), a "convergência pode ser percebida nos conteúdos, nos dispositivos terminais e nos sistemas de rede" ${ }^{2}$. Na comunicação, costuma-se falar da convergência como sinônimo da convergência de formato, o mesmo que multimídia ou "multimeios" (SANTAELLA, 2003), isto é, a conjugação, em apenas um espaço, de vários formatos midiáticos, como imagem, texto, vídeo, link etc. Outro tipo de convergência é a de terminais, que reúne as funçôes de vários meios de comunicação em apenas uma ferramenta. Contudo, o teórico Henry Jenkins (2008, p. 27-28) vai de encontro à ideia de a convergência "ser compreendida principalmente como um processo tecnológico que une múltiplas funçôes dentro dos mesmos aparelhos", pois, embora isso ocorra, nunca vai haver um meio que englobe todas as características dos outros, bem como uma substituiçáo.

Assim, encontramos a convergência de conteúdo, sobre a qual nos debruçamos e damos ênfase. Este tipo de convergência tem a ver com a transposição de arquivos de um meio para outro, majoritariamente, do impresso, do rádio e da TV para a web. Como a convergência de conteúdo se tornou bastante comum entre os meios de comunicaçáo, acreditamos que os jornalistas podem fortalecer seu trabalho por meio dessa possibilidade. E é nesta seara onde as narrativas crossmidiáticas e transmidiáticas podem surgir de maneira mais eficaz.

A expressão transmídia (ou narrativa transmidiática) nasceu na área do entretenimento com a ideia de expansão de um assunto para diversos meios, para que o receptor (fâ) acompanhe essa migração, consumindo os desdobramentos da temática em vários dispositivos. Esse conteúdo tem de ser diferente e independente daquele que inspirou inicialmente o assunto, explorando novos pontos de vista e expandindo algo que náo havia recebido destaque. Ainda que focalize o fă, o produto pode ser consumido por um iniciante, haja vista que cada material tem uma narrativa independente.

Por sua vez, a narrativa crossmidiática (ou crossmídia), surgida na área do marketing e da publicidade, possui um conceito fluido, tendo em vista que muitos utilizam a expressão ou como sinônimo de convergência (ANTIKAINEN et al., 2004; CORREIA E FILGUEIRAS, 2008), de transmídia (CORREIA E FILGUEIRAS, 2008; DENA, 2004; MÉDOLA, 2009) ou mesmo sem precisar o termo (CORREIA E FILGUEIRAS, 2008). Em nosso estudo, entendemos crossmídia como um cruzamento midiático. Ela acontece quando um veículo direciona ou indica o espectador para outro, para que se possa consumir determinado conteúdo ou interagir, podendo até, por exemplo, nos remeter de volta ao meio inicial para que vejamos o produto finalizado (com nossa interaçáo ou mesmo de outros, quando se necessita de uma votaçáo, por exemplo). Por conseguinte, o diálogo acontece entre as mídias - o aspecto tecnológico -e não entre os conteúdos, como na narrativa transmidiática.

Além de diferenciar conceitualmente e empiricamente as duas narrativas, demonstraremos que elas podem ser percebidas na área jornalística, ainda 
que não tenham sido criadas para esta. E nesse limiar da "cultura da convergência", as empresas "passam a requerer de seus profissionais novas competências diante das exigências da plataforma convergente", conforme acredita Ana Sílvia Médola (2009, p. 4). Nessa linha, os jornalistas podem revigorar sua profissão através da aplicação das narrativas cross e transmidiáticas conjuntamente, ou não, com os conteúdos transpostos.

\section{Narrativa crossmidiática ou cruzamento de mídia}

Apesar da existência da narrativa crossmidiática não estar condicionada exclusivamente à internet, foi neste meio que os cruzamentos de mídia começaram a ser mais evidenciados. Em um de seus relatórios, Boumans (apud CORREIA e FILGUEIRAS, 2008) defende que a mídia cruzada se tornou mais sintomática no final dos anos noventa, através da criação do programa televisivo Big Brother, na Holanda. Na ocasião, a interação entre mídia televisiva e web ganhou mais evidência, sobretudo no contexto da crossmídia, haja vista que o programa guiava a audiência para web, para que o público interagisse e depois voltasse à TV e assistisse ao programa.

No Brasil, o primeiro caso de cruzamento de mídia sem a necessidade explícita da internet é proporcionado pela Globo Filmes, diz a pesquisadora Luiza Lusvarghi (2007). De acordo com a autora (2007, p. 2), o filme Antonia conseguiu articular esse cruzamento através do filme e do seriado. Ainda assim, Lusvarghi explica que o Big Brother brasileiro já fazia "amplo uso dessa ferramenta de marketing" (2007, p. 2), porém, realizando o cruzamento ente TV e web, semelhante ao que ocorreu na Holanda.

Embora não possamos dizer que o cruzamento midiático tenha surgido com a web, sobretudo na interação com a TV, foi com esses dois meios que a crossmídia ganhou mais relevância. Os pesquisadores Antikainen et al. (2004, p. 28) descrevem o cenário das primeiras experiências de crossmídia evidenciadas por eles: "TV-SMS foi a primeira solução desenvolvida na chamada TVweb (em 1999), onde uma tela foi criada para conteúdos da Internet: artigos, tempo e imagens de câmera da web" ${ }^{3}$. Além dessas experiências entre TV, internet e telefonia móvel, através de SMS (serviço de mensagem curta, em inglês "short message service"), Antikainen et al. (2004, p. 28) observam que "pesquisas de opinião são produtos típicos da crossmídia, do ponto de vista da interação da transmissão televisiva" ${ }^{4}$.

O conceito de crossmídia surgiu na área da publicidade e do marketing, como já mencionado de maneira apressada, através da "possibilidade de uma mesma campanha, empresa ou produto utilizar simultaneamente diferentes tipos de mídia: impressa, TV, rádio e Internet” (LUSVARGHI, 2007, p. 2). Contudo, esse uso não acontece veiculando o mesmo conteúdo em outro meio, isso seria convergência (de conteúdo).

Segundo a pesquisadora Celia Quico, "define-se Cross-Media como um produto e/ou serviço interativo que envolve mais do que um medium" (2004, p. 2, grifo do original). Se levarmos em consideração a ideia de interativo como a indicação ou guia de um meio para outro, em outras palavras, 
que uma mídia direciona o espectador para outra, assim, encontramos a narrativa crossmidiática. Esse entendimento de crossmídia como direcionamento, guia e indicação é também compartilhado por De Haas, afirmando que "a narrativa direciona o receptor de uma mídia para a seguinte" (apud CORREIA E FILGUEIRAS, 2008, p. 4).

Miyamaru et al. (2008) defendem que a crossmídia tem várias maneiras de experimentação. No entanto, algumas dessas aplicações expressas pelos pesquisadores são sinônimas de convergência ou transmídia, como se a crossmídia fosse um conceito maior, abarcando todos os outros. Contudo, entre as formas de uso que os autores especificam, uma é semelhante ao que conceituamos como narrativa crossmidiática: "call-to-action (CTA) é uma forma de indicar e incentivar o usuário que a continuaçáo da história pode ser realizada em outra mídia. Pode ser abstraído como um hyperlink entre diferentes meios de comunicação" (MIYAMARU et al., 2008, p. 4).

Os autores Antikainen et al. dão um exemplo de como pode haver narrativa crossmidiática, no mesmo sentido que conferimos ao termo: "Crossmídia é usada para enviar alerta a um terminal (telefone móvel) e então conectar um outro terminal (o computador e a Internet) para se registrar alertas e se juntar mais informaçóes do tema" ${ }^{5}$ (2004, p. 30). A propósito, a narrativa crossmidiática como guiadora é defendida ainda desse modo, em certo momento, pela brasileira Lucia Filgueiras (apud CORREIA E FILGUEIRAS, 2008, p. 5): "crossmídia é o meio de suporte de múltipla colaboração utilizado para liberar uma simples história, ou tema, na qual a narrativa direciona o público de um meio para outro, utilizando a força de cada meio para dialogar"'.

Para a pesquisadora sobre crossmídia e transmídia, Christy Dena, as interações e os diálogos entre os meios de comunicação podem ser de três modos: cross channel; inter-channel; intra-channel. No cross channel, o usuário muda de mídia e começa a interação numa outra, que exige posicionamentos e trabalhos cognitivos singulares: "o usuário pode estar sentado exatamente no mesmo lugar, lendo um livro na sua mesa e então usar a Internet, mas tem de mudar sua interação (de passar páginas para teclar no teclado) e seus processos cognitivos de raciocínio para 'desenvolver' novos esforços" 7 (DENA, 2004, p. 4).

$\mathrm{Na}$ interação inter-channel, o consumidor não muda de canal (isto é, o meio de comunicaçáo), porém de formato. Por exemplo, deixa de ler um texto para assistir a um vídeo, no mesmo endereço ou em outro, contato que não mude de mídia: "Navegação inter-channel envolve a ação dentro de um canal, mas entre modos [que denominariamos de formato]. Por exemplo, ir de um texto na web para uma sequência de vídeo" ${ }^{8}$ (DENA, 2004, p. 4, grifo nosso). Por fim, a navegação intra-channel é aquela em que o navegante não muda nem de canal, nem de formato: "Navegaçáo intra-channel acontece dentro de um mesmo canal e formato. Um exemplo pode ser observado quando se avança uma gravaçáo de áudio para o momento de uma fala do narrador" ${ }^{9}$ (DENA, 2004, p. 5).

O conceito de crossmídia é utilizado de modo confuso, como equivalente à convergência ou, mais comumente, à transmídia, ou mesmo de maneira imprecisa e abrangente. Em certos momentos, os autores Antikainen et 
al. falam de crossmídia aproximando com o entendimento de convergência: "Crossmídia se refere ao conteúdo distribuído em várias mídias" ${ }^{10}$ (2004, p. 3). Aqui, os autores defendem que um conteúdo perpassado (ou convergido) por várias mídias seria exemplo de crossmídia, ao invés de convergência. Todavia, a crossmídia não tem a ver com conteúdo convergido, mas com a indicação para outro meio, guiando a audiência para outra mídia. Antikainen et. al (2004, p. 7) defendem, erroneamente, portanto, que "uma publicidade crossmídia tem o conteúdo disposto de forma impressa e digital, isto quer dizer possibilidade de difusão do mesmo conteúdo por meio de diversas ferramentas" ${ }^{11}$.

Os pesquisadores brasileiros, Correia e Filgueiras, em dado momento, também utilizam o conceito de crossmídia como sinônimo de convergência, afirmando que, na crossmídia, o conteúdo é "acessível/entregue em uma série de dispositivos como PC's, dispositivos móveis, TV ou caixas set-top" (2008, p. 3). Correia e Filgueiras (2008, p. 4) trazem ainda autores como os supracitados Antikainen et al. (2004), que, de modo semelhante, tratam crossmídia como sinônimo de convergência, esclarecendo que aquela acontece quando "o mesmo conteúdo é transmitido por diferentes mídias, valendo-se dos benefícios individual de cada meio". ${ }^{12}$

A autora Ana Silvia Médola (2009), por sua vez, não distingue crossmídia de transmídia. No primeiro momento, refere-se claramente à narrativa crossmidiática, pois fala de "convocação", isto é, a indicação de outro meio ao espectador; enquanto, no segundo, traz um exemplo de transmídia, que seria a ampliaçáo de um assunto veiculado em outro meio, sem a necessidade de indicação (quando existiria crossmídia).

O exemplo mais recorrente é a convocação para que o telespectador acesse o site da emissora para obter mais detalhes e informaçôes sobre o conteúdo veiculado na TV, no caso dos programas informativos. Mas também as telenovelas, as séries, os reality shows, todos têm uma página na internet na qual o telespectador poderá encontrar de blogs com participação de autores à ficha técnica da equipe de produção (MÉDOLA, 2009, p. 4).

Os estudiosos Danilo Correio e Lucia Filgueiras (2008, p. 3) também utilizam crossmídia como semelhante à transmídia e ainda ampliam o conceito de ambos, afirmando que, para existir cruzamento de mídia, "mais de um meio precisa dar suporte a um tema ou história, assim como estabelecer uma meta ou um propósito, e pretender transmitir uma mensagem”. Nessa perspectiva, os autores tratam transmídia e crossmídia como sinônimos, incluindo propósitos e metas como essenciais ao processo.

Mais explicitamente, a australiana Christy Dena $(2004$, p. 2) usa crossmídia como sinônimo de transmídia. Para Dena, os fatos que Jenkins (2008) descreve como transmidiáticos são também crossmidiáticos, visto que as expressôes são equivalentes. Segundo a autora, os exemplos citados por Jenkins sobre a franquia Matrix ${ }^{13}$ são fatos de crossmídia. Ainda assim, como na série não há divulgação de um meio ao outro, ou seja, o espectador não é levado de uma mídia para a seguinte - o que seria próprio da narrativa crossmidiática 
-, entendemos que a narrativa na franquia Matrix seria um caso da narrativa transmidiática.

Como se percebe, os estudiosos que tratam de crossmídia são imprecisos quanto ao termo. Em vários instantes, os pesquisadores referidos precisam o termo com clareza, porém, quando tornam a fazê-lo no mesmo trabalho, às vezes não fazem distinção com outras expressốes, como transmídia e convergência, usando-as como sinônimas ou mesmo conceituando crossmídia de maneira muito abrangente. Fato esse que pode ser percebido por meio das citaçôes, nas quais um mesmo autor ajuda a definir crossmídia, mas também a mostrar as falhas de conceituação dessa expressão.

Por fim, em nossa concepção, na narrativa crossmidiática, a intenção não é expandir o conteúdo, mas promovê-lo. Portanto, o diálogo principal não é com o assunto, com a temática ou com o contexto, mas com o meio. Sentir-se atraído, guiado e direcionado para ir a outra mídia, independentemente do motivo.

\title{
Narrativa transmidiática ou ampliação de tema
}

A narrativa transmidiática tem seu surgimento mais preciso do que a crossmídia, bem como seu mentor. O pesquisador norte-americano Henry Jenkins (2008) deu nome a algo que já acontecia, mas que não havia sido estudado sistematicamente. Da área do entretenimento, "a narrativa transmidiática refere-se a uma nova estética que surgiu em resposta à convergência das mídias - uma estética que faz novas exigências aos consumidores e depende da participação ativa de comunidades de conhecimento" (JENKINS, 2008, p. 47). Para ser mais explícito, na transmídia, o consumidor segue os desdobramentos de uma temática por meio de várias mídias. Em outras palavras:

\begin{abstract}
os consumidores devem assumir o papel de caçadores e coletores, perseguindo pedaços da história pelos diferentes canais, comparando suas observaçóes com as de outros fãs, em grupos de discussáo on-line, e colaborando para assegurar que todos os que investiram tempo e energia tenham uma experiência de entretenimento mais rica (JENKINS, 2008, p. 47).
\end{abstract}

Como no âmbito do entretenimento o fã ganha relevância, é nesta área que a transmídia se torna mais clara, pois uma franquia ganha desdobramentos em jogos eletrônicos e filmes, principalmente. Numa narrativa transmidiática, por exemplo, o jogo traz elementos que ajudam a complementar as brechas deixadas no filme, e vice-versa. Por conseguinte, "uma história transmidiática se desenrola através de múltiplos suportes midiáticos, com cada novo texto contribuindo de maneira distinta e valiosa para o todo. $\mathrm{Na}$ forma ideal de narrativa transmidiática, cada meio faz o que faz de melhor" (JENKINS, 2008, p. 135).

Todavia, um produto transmidiático deve permitir que um espectador não-fã possa consumi-lo, em outras palavras, não deve fazer com que seja imprescindível jogar o game para assistir ao filme, ou mesmo ter de ver o filme para jogar o game. Ou seja, como Jenkins explica, "cada acesso à franquia deve ser autônomo, para que não seja necessário ver o filme para gostar do game, e 
vice-versa. Cada produto determinado é um ponto de acesso à franquia como um todo" (2008, p. 135). Portanto, se um meio náo trouxer complemento para o produto de outra mídia, não há narrativa transmídia, pois não há ampliação do tema ou assunto. Isso ocorre, por exemplo, quando

Hollywood age como se tivesse apenas de proporcionar mais do mesmo, imprimindo um logotipo de Jornada nas Estrelas [Star Trek] (1966) em um monte de bugigangas. Na realidade, o público quer que o novo trabalho ofereça novos insights e novas experiências (JENKINS, 2008, p. 146).

Henry Jenkins defende que os produtores têm de "desenvolver games que náo apenas levem as marcas de Hollywood a um novo espaço midiático, mas que também contribuam para um sistema maior de narrativa" (2008, p. 146). Em suma, as franquias não devem apenas repetir, mas desdobrar e ampliar aquele universo já existente.

Com essa explicação, percebemos que o entendimento de transmídia não sofre tantas confusôes conceituais quanto o de crossmídia. Como a autoria da expressão transmídia é bem evidenciada ao americano Henry Jenkins, que a esmiúça em seu livro "Cultura da Convergência" (2008) por meio de teorias e demonstrações empíricas, as ambiguidades só surgem devido à crossmídia, aplicada algumas vezes como seu sinônimo. O problema quanto ao que se refere crossmídia se deve ao fato de ela não possuir uma produção bibliográfica consistente teoricamente e empiricamente que lhe dê sustento.

\section{As narrativas midiáticas no webjornalismo}

De acordo com Monique de Haas, "comunicação crossmídia é a comunicação onde a narrativa direciona o receptor de um meio para o próximo" ${ }^{14}$ (apud CORREIA E FILGUEIRAS, 2008, p. 4). Cabe explicar que De Haas fala de "comunicação crossmídia" (no original: "cross media communication") já num sentido da aplicação dessa narrativa no jornalismo, haja vista que "a base do conceito de mídia cruzada tem origem na área de publicidade e evoluiu para outras áreas conforme a necessidade dos diferentes autores em aproveitá-lo" (apud CORREIA e FILGUEIRAS, 2008, p. 14). Os pesquisadores Antikainen et al. explicam que a "cross media communication", expressão que os autores também usam para referir-se à crossmídia no jornalismo, "é a comunicação onde a narrativa guia a audiência de uma mídia para outra” ${ }^{15}$ (2004, p. 7). Portanto, embora náo tenha nascido na área jornalística, pesquisadores de diversas áreas do conhecimento se valem desse conceito, bem como os de jornalismo, que utilizam até a nomenclatura "cross media communication".

Como já dissertamos, embora a narrativa crossmidiática ganhe bastante visibilidade com a relação entre TV e web, ela não necessariamente precisa dos dois meios para existir. Um exemplo de crossmídia no jornalismo pode ser observado quando a revista Super Interessante guia seu leitor para seu site - ver Imagem 1. Neste caso específico, pode-se conferir na internet a reportagem exposta na revista (convergência), bem como um desdobramento de seu assunto (transmídia). 


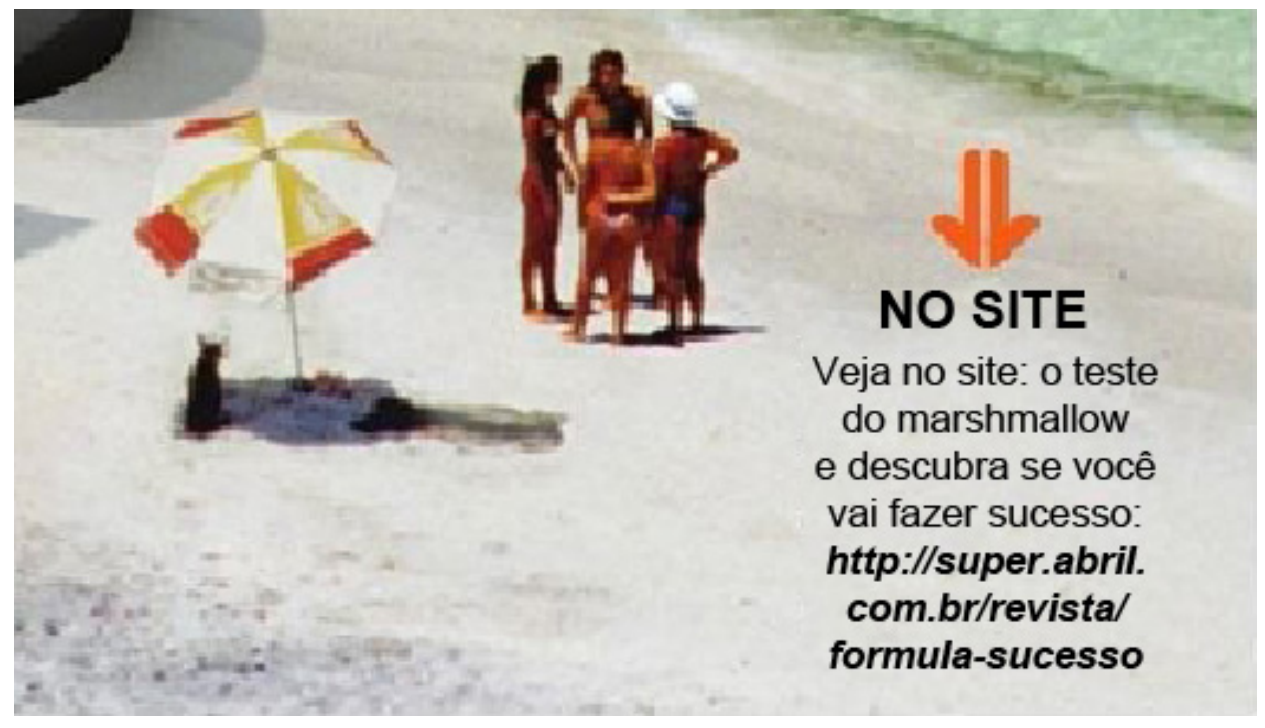

Imagem 1: Crossmídia na Super Interessante por motivos de convergência e transmídia

Além da utilização da crossmídia para o jornalismo nesses dois casos, o espectador pode ser guiado com finalidades de propaganda e marketing. Em outras palavras, não existindo aprofundamento do tema (característico da transmídia) ou convergência do conteúdo, porém apenas divulgação e publicidade. A narrativa crossmidiática usada com este fim (de publicidade e marketing) pode ser exemplificada ainda com um caso na revista Super Interessante - ver Imagem 2. Nesta situação, a Editora Abril se utiliza da crossmídia na revista para promover sua campanha.

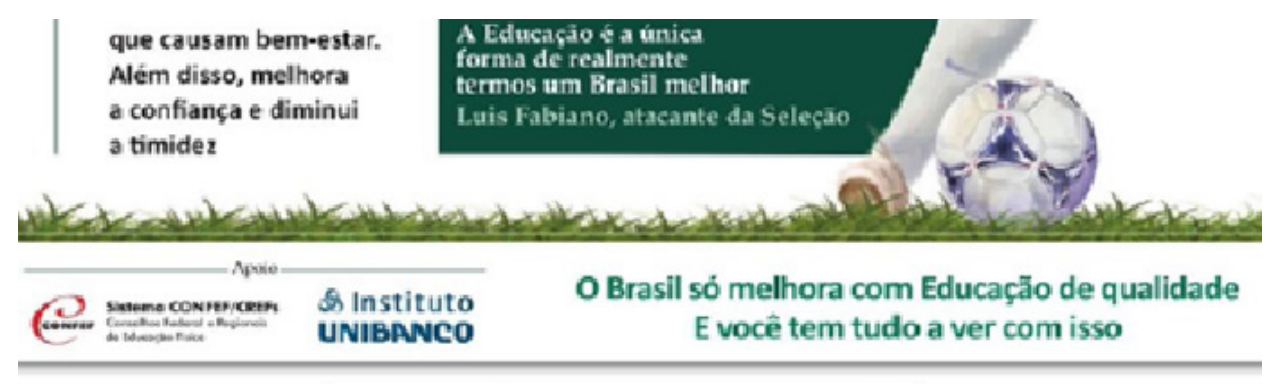

www.educarparacrescer.com.br

Imagem 2: Campanha da Editora Abril divulgada através de crossmídia na Super Interessante ${ }^{17}$

Enquanto a crossmídia possui a expressão "comunicação crossmídia” para se referir à sua utilização no jornalismo, a transmídia ainda não obtém um estudo táo estruturado nesta área. Contudo, se definirmos transmídia como ampliação, desdobramento ou mesmo complementação de um assunto através de mais de uma mídia, essa narrativa se enquadra no âmbito jornalístico, sobretudo na internet. Com as novas configuraçóes da webjornalismo, entra em cena um espaço maior para publicação e longe das amarras temporais, como o fechamento ${ }^{18}$. Por conseguinte, uma matéria publicada em um meio pode ganhar contornos e desdobramentos na internet. Ainda que esta mídia não seja primordial para a existência da transmídia, as especificidades que o jornalismo adquire nela facilitam seu emprego. 
No webjornalismo, a transmídia pode acontecer aliada à convergência dos materiais, valendo-se de outras de suas características do meio, como a memória e a hipermídia (MIELNICZUK, 2003; PALACIOS, 2002, 2003). Steven Johnson aponta, por exemplo, que "o mundo on-line propicia recursos que ajudam a sustentar a programação mais complexa em outros meio de comunicação" (2005, p. 92). Quando um conteúdo transposto (convergência) traz hiperlinks para matérias mais antigas (memória), esse fenômeno se perfaz como narrativa transmidiática, pois há uma ampliação da temática inicialmente abordada em outro meio - ver Imagem 3. Como é o caso desta matéria convergida do Jornal Hoje da TV para seu site, onde uma matéria sobre moda (na TV e também no site, tendo em vista que foi convergida) amplia a temática por meio de uma entrevista com um consultor da área.

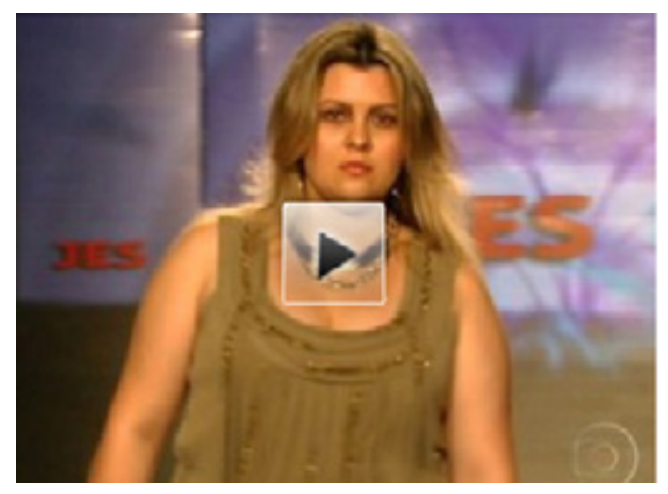

O consultor em moda Reginaldo Fonseca explica o que cai bem e as roupas mais indicadas para quem veste manequim acima de 46. Os tecidos mais grossos podem disfarçar a gordura localizada. Leia 3qui a integra do bate papo com o
consultor.

Imagem 3: Matéria convergida do Jornal Hoje da TV para o site tem narrativa transmidiática com hiperlink ${ }^{19}$.

Ainda assim, esses desdobramentos podem ocorrer de maneira mais tácita, isto é, sem a crossmídia e sem a convergência. É neste ponto que se faz necessário um olhar mais atento do pesquisador, tentando verificar qual conteúdo pode ser considerado um desdobramento ou ampliação de outro que foi veiculado em outro meio.

\section{Considerações finais}

Notamos que, inconscientemente ou não, ambas as narrativas já são aplicadas ao jornalismo. A crossmídia possui tanta evidência que os pesquisadores da área criaram o termo "comunicação crossmídia" para se referir ao seu uso no jornalismo. A narrativa é observada não só em revistas, como exemplificado anteriormente; ao contrário, os telejornais Jornal Hoje, Jornal Nacional e Jornal da Globo, todos da Rede Globo de televisão, incorporam a crossmídia em sua produção noticiosa diária. Ao final de grande parte das reportagens ou das notícias lidas pelos apresentadores é colocado o site do telejornal na tela. Com o endereço, o espectador é guiado para a internet para rever os materiais que foram exibidos nos telejornais ou mesmo para acompanhar os possíveis desdobramentos dos mesmos.

Em contrapartida ao amplo uso e estudo da narrativa crossmidiática, a transmídia não é estudada na área jornalística e não é observada com tanta facilidade. Essa dificuldade ocorre pois a ampliação pode existir sem uma 
indicação direta (com crossmídia ou com hiperlinks, no caso de materiais convergidos), exigindo que o espectador e o pesquisador consumam os conteúdos de uma mesma empresa através de suas várias mídias, analisando se determinado assunto obteve ampliação em outro meio. Embora seja mais comum que as narrativas aconteçam entre TV e web, sobretudo desta para aquela, em 20 de julho, observamos crossmídia e transmídia da web para a TV (ver Imagem 4). Nesta situação, o apresentador do programa televisivo Globo Esporte, Thiago Leifert, complementa uma notícia veiculada no portal Globo Esporte, indicando a mesma numa tela colocada no estúdio.

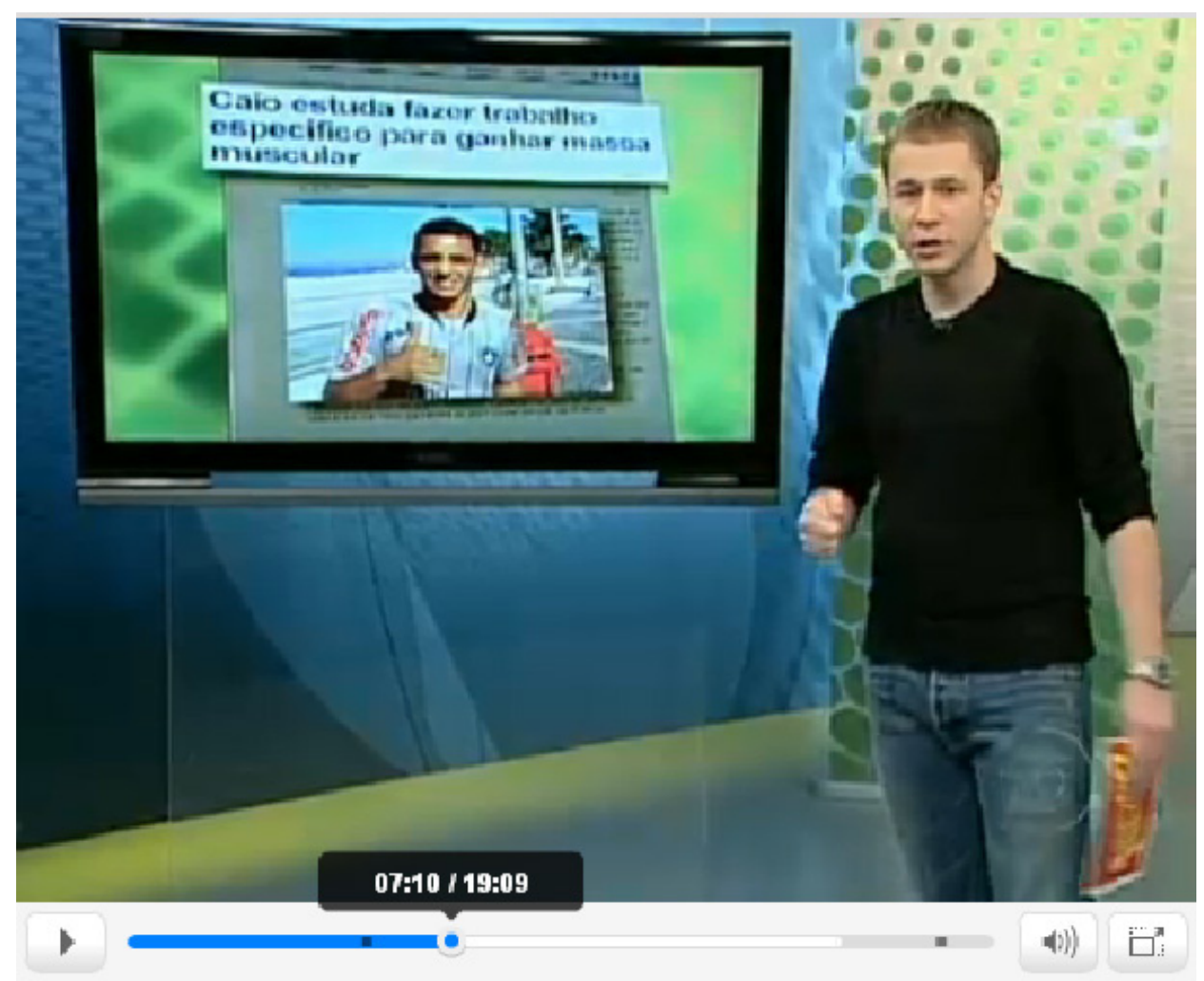

Imagem 4: Thiago Leifert indica site Globo Esporte como fonte de matéria do programa. ${ }^{20}$

Obviamente, não é apenas através da crossmídia e da transmídia que o jornalista pode revigorar seu trabalho, sobretudo na web. Características do webjornalismo - como a memória e a hipermídia - podem ajudar a elevar o processo de construção de notícia, principalmente quando aliada à convergência. Uma matéria pode ser interligada com outra através dos hiperlinks, seja esse material componente do banco de dados (memória) do próprio veículo (intratextual) ou de outro espaço da internet (intertextual). Se uma notícia tiver sido convergida de outro meio para a web e trouxer links para outros textos, essa ampliação de abordagens é considerada uma narrativa transmidiática; e o jornalista terá elevado ainda mais a construção desse discurso se o material (na primeira mídia) trouxer uma indicação (crossmídia) de que na web há um desdobramento do assunto e sua convergência.

Um exemplo - apenas à guisa de demonstração porque vários outros poderiam ser citados - de uso eficaz das narrativas cross e transmidiáticas - aliadas às especificidades do webjornalismo da memória, hipermídia e convergência - acontece 
no telejornal Jornal Hoje. Percebemos que uma matéria trouxe a narrativa crossmidiática, indicando a convergência do material para o site. $\mathrm{O}$ assunto era sobre a doação de dinheiro para as vítimas decorrente das enchentes de junho deste ano no Nordeste ${ }^{21}$. Quando acessamos o site do Jornal Hoje, observamos que essa matéria convergida (endereço no rodapé) traz um link intratextual (aquele que sugere algo dentro do próprio site) para uma notícia exclusiva da internet - na qual eram mostrados os endereços dos postos para doaçáo de dinheiro e para ser voluntário. Trazia ainda um link intertextual (indicando outro espaço da web), que nos direcionava para o site da Ação Global (endereço no rodapé).

O entrelaçamento criado tanto pela crossmídia e transmídia quanto pela aliança da convergência, memória e hipermídia não torna necessariamente o conteúdo mais crítico. Essas estratégias construtivas aumentam a polifonia, ampliam uma temática abordada, atravessando até transversalmente mais de uma mídia. Esse alargamento do assunto pode acontecer tanto de maneira intratextual (direcionando as indicaçóes para a própria empresa) como para fora dela (intertextual). Além do mais, essas informaçôes adicionais possibilitam ao jornalista dispor de uma pluralidade de visóes em um texto, indo desde as apreciaçôes oficiais (órgãos públicos, políticos, assessores etc.) até as alternativas, como blogs, sites independentes, entre outros.

\section{Referências Bibliográficas:}

ABREU, Jorge; BRANCO, Vasco. A convergência TV-web: motivaçôes e modelos. In: BOCC - Biblioteca On-line de Ciências da Comunicação, Portugal, 1999. Disponível em: <http://www.bocc.ubi.pt/pag/abreu-ferraz-convergencia-TV-Web.pdf>. Acesso em: 25 de outubro de 2009.

ANTIKAINEN, Hannele; KANGAS, Sonja; VAINIKAINEN, Sari. Three views on mobile cross media entertainment. In: VTT Information Technology, Research Report, 2004. Disponível em: <http://www.souplala.net/show/crossmedia_entertainment.pdf $>$. Acesso em: 21/05/2010.

CORREIA, Danilo; FILGUEIRAS, Lucia. Introdução à mídia cruzada. In: Grupo de Estudos em interação do LTS, Escola Politécnica da Universidade de São Paulo, 2008. Disponível em: <http://lts-i.pcs.usp. br/xgov/pub/TutorialMidiaCruzada.pdf >. Acesso em: 18/05/2010.

DENA, Christy. Current State of Cross Media Storytelling: Preliminary observations for future design. In: European Information Society Technologies (IST) Event, Netherlands, 2004. Disponível em: <http://www.christydena.com/ Docs/DENA_CrossMediaObservations.pdf >. Acesso em: 18/05/2010.

FERRARI, Pollyana. A rizomática aventura da hipermídia. Uma análise da narrativa no ambiente digital. Tese de Doutorado. São Paulo: USP, 2007. . Jornalismo digital. São Paulo: Contexto, 2003.

JENKINS, Henry. Cultura da convergência. São Paulo: Aleph, 2008.

JOHNSON, Steven. Cultura da interface: como o computador transforma nossa maneira de criar e comunicar. Rio de Janeiro: Jorge Zahar Editor, 2001. 
LUSVARGHI, Luiza. O cinema na era digital: a consolidação dos conteúdos cross-media no Brasil, de Big Brother ao caso Antônia. In: XXX Congresso Brasileiro de Ciências da Comunicação, Intercom Nacional, Santos-SP, 2007. Disponível em: <http://www.intercom.org.br/papers/ nacionais/2007/resumos/R1059-2.pdf >. Acesso em: 1/10/2009.

MÉDOLA, Ana. Televisão digital brasileira e os novos processos de produção de conteúdos- os desafios para o comunicador. In: Revista da Associação Nacional dos Programas de Pós-Graduação em Comunicação, E-Compós, Brasília-DF, v. 12, n. 3, p. 1-12, 2009. Disponível em: <http://www. compos.org.br/seer/index.php/e-compos/article/viewFile/379/376>. Acesso em: 1/06/2010.

MIELNICZUK, Luciana. Jornalismo na web: Uma contribuição para o estudo do formato da notícia na escrita hipertextual. Tese de Doutorado. Salvador, UFBA, 2003.

MIYAMARU et al. Qualidade da informação em sistemas convergentes cross-media. Artigo produzido para a disciplina "Qualidade de dados" da Escola Politécnica da Universidade de São Paulo, 2008. Disponível em: <http://lts-i.pcs.usp.br/xgov/pub/anexos_xgov/@0048\%20

MIYAMARU\%20DOMINGUES\%20Qualidade\%20da\%20informacao $\% 20 \mathrm{em} \% 20$ sistemas $\% 20$ convergentes $\% 20$ cross-media>. Acesso em: 27/10/2009.

PALACIOS, Marcos. A memória como critério de aferiçāo de qualidade no ciberjornalismo: alguns apontamentos. In: Revista FAMECOS, v. 37, p. 91-100, 2008. Disponível em: <http://revcom.portcom.intercom.org.br/index.php/famecos/article/viewFile/5560/5044>. Acesso em: 14 de outubro de 2009.

Jornalismo online, informação e memória: apontamentos para debate. In: Workshop de Jornalismo Online, 2002, Covilhã - Portugal. Disponível em: <http://www.facom.ufba.br/jol/pdf/2002_palacios_informacaomemoria.pdf $>$. Acesso em: 27 de outubro de 2009.

- Ruptura, continuidade e potencialização no jornalismo online: o lugar da memória. In: MACHADO, Elias \& PALACIOS, Marcos (orgs.). Modelos do Jornalismo Digital. Salvador: Editora Calandra, 2003. Disponível em: <http://www.facom.ufba.br/JOL/pdf/2003_palacios_ olugardamemoria.pdf>. Acesso em: 27 de outubro de 2009.

QUICO, Celia. Cross-media em emergência em Portugal: o encontro entre a televisão interactiva, as comunicaçóes móveis e a Internet. In: Televisão Interactiva: conteúdos aplicaçôes e desafios. Universidade Lusófona de Humanidades e Tecnologias, Lisboa: CRL, 2004.

SANTAELLA, Lucia. Culturas e artes do pós-humano. São Paulo: Paullus, 2003.

. Linguagens líquidas na era da mobilidade. São Paulo: Paullus, 2007.

WARD, Mike. Jornalismo online. São Paulo: Roca, 2006. 


\section{Notas}

1 - Artigo referente à parte do TCC intitulado Crossmídia e Transmídia no Globo Esporte: As Narrativas Midiáticas e as Propriedades da Convergência, Memória e Hipermídia.

2 - T.N.: "Convergence can be seen in contents, terminal devices and networking systems".

3 - T.N.: "First TV-SMS solutions were developed in so called Tvweb (in 1999) where a screen is created from Internet content: articles, weather and web camera images".

4 - T.N.: "Polls are a typical form of cross media, from the viewpoint of interactive television broadcasting".

5 - T.N.: "Cross media is used to get alert on one terminal (mobile phone) and then $\log$ on to another terminal (PC and the Internet) to follow up alerts and gather more information of the subject".

6 - T.N.: "Crossmedia is the collaborative support of multiple media to delivering a single story or theme, in which the storyline directs the receiver from one medium to the next, according to each medium's strength to the dialogue".

7 - T.N.: "The user may be sitting in the exactly the same spot, reading a book at their desk and then using the Internet, but they have to change their interaction (from turning pages to taping a keyboard) and the associated cognitive processes to 'build' the work".

8 - T.N.: "Inter-channel navigation involves the movement within a channel and between modes. For example, moving from a text-based webpage to a video sequence".

9 - T.N.: "Intra-channel navigation therefore, is within the same channel and within the same mode. An example would be fast-fowarding through an audio recording at the request of the narrator".

10 - T.N.: "Cross media refers to content distributed through multiple media".

11 - T.N.: "In marketing cross media means both printed and digital content, for broadcasters it means possibilities to broadcast same content to different devices".

12 - T.N.: "The same content is transmitted through different media drawing on the benefits of each individual médium".

13 - Em seu livro, Jenkins (2008) esclarece que as narrativas dos jogos de Matrix completam brechas deixadas nos filmes da franquia, bem como o filme traz informações inéditas que o jogo não possui. Todavia, o autor afirma que cada meio aborda o assunto de maneira completa, isto é, o consumidor não precisa ter acesso a todos os produtos para entender a história, elas são autossuficientes.

14 - T.N.: "Cross media communication is communication where the storyline will direct the receiver from one medium to the next".

15 - T.N.: "Is communication where the storyline will direct the receiver from one medium to the next".

16 - Material veiculado na SUPER INTERESSANTE. São Paulo-SP: Editora Abril, jul. 2010, p. 67.

17 - Matéria publicada na SUPER INTERESSANTE. São Paulo-SP: Editora Abril, jul. 2010, p. 40.

18 - Em jargão jornalístico, fechamento se refere à hora final que um veículo deve reunir as matérias para começar a pensar como melhor organizá-las na publicação; também conhecido como deadline. 
19 - Matéria do Jornal Hoje de 21/07/2010 veiculada na TV e no site do telejornal. Disponível em: <http://g1.globo.com/jornal-hoje/noticia/2010/07/dicas-demoda-deixam-gordinhas-bem-vestidas.html>. Acesso em: 21/07/2010.

20 - Notícia exibida no programa Globo Esporte e no portal em 20/07/2010. Disponível em: $<$ http://globoesporte.globo.com/futebol/times/botafogo/noticia/2010/07/caio-estudafazer-trabalho-especifico-para-ganhar-massa-muscular.html >. Acesso em 03/08/2010.

21 - Matéria publicada no site do Jornal Hoje em 23/06/2010. Disponível em: <http://g1.globo.com/jornal-hoje/noticia/2010/06/campanha-copasolidariaarrecada-donativos-para-vitimas-de-enchentesjh.html>. 